\title{
The Prevalence of Metabolic Syndrome and Its Related Factors among Adults in Palestine: A Meta-Analysis
}

\author{
Abdel Hamid el Bilbeisi ${ }^{1}$, Sakineh Shab-Bidar ${ }^{2}$, Diane Jackson ${ }^{3}$, Kurosh \\ Djafarian $^{1 *}$
}

OPEN ACCESS

Citation: Abdel Hamid el Bilbeisi, Sakineh Shab-Bidar, Diane Jackson, Kurosh Djafarian. The Prevalence of Metabolic Syndrome and Its Related Factors among Adults in Palestine: A Meta-Analysis. Ethiop J Health Sci 2017;27(1):77-84. doi: http://dx.doi.org/10.4314/ejhs.v27i1.10.

Received: August 4, 2016

Accepted: October 9, 2016

Published: January 1, 2017

Copyright: Abdel Hamid B, et al. This is

an open access article distributed under

the terms of the Creative Commons

Attribution License, which permits

unrestricted use, distribution, and

reproduction in any medium, provided the

original author and source are credited.

Funding: None

Competing Interests: The authors

declare that this manuscript was approved

by all authors in its form and that no

competing interest exists.

Affiliation and Correspondence:

${ }^{1}$ Department of Clinical Nutrition,

School of Nutritional Sciences and

Dietetics, Tehran University of

Medical Sciences - International

Campus IC-TUMS) Tehran, Iran

${ }^{2}$ Department of Community Nutrition,

School of Nutritional Sciences and

Dietetics, Tehran University of

Medical Sciences, Tehran, Iran

${ }^{3}$ Public Health Nutrition Research

Group, Rowett Institute of Nutrition

and Health, Aberdeen University,

Aberdeen, Scotland, UK

*Email: kdjafarian@tums.ac.ir

\section{ABSTRACT}

BACKGROUND: Metabolic syndrome (MetS)is increasingly becoming a challenging public health issue in Palestine. The current burden of MetS in the country is unknown. There has been limited research on the prevalence of MetS. This meta-analysis is the first to estimate the population prevalence of MetS and its related factors among adults in Palestine.

METHODS: A PRISMA systematic search appraisal and metaanalysis were conducted. A systematic literature search of PubMed, Scopus and Google Scholar was conducted in December 2014 up to February 2015. Generic, methodological and statistical data was extracted from the eligible studies which reported MetS prevalence. $A$ random effect meta-analysis was conducted on crude MetS prevalence rates. Heterogeneity was assessed by Cochran's $Q$ and $I^{2}$ tests. Subgroup analyses were also performed according to the predefined criteria.

RESULTS: The literature search yielded a total of 49 studies. Eight papers were included in the final analysis with sample size ranging 163 to 992. In addition, 2937 cases with MetS among people aged 15 years or more were estimated in Palestine between 2001 and 2014. There was high heterogeneity among studies $\left(I^{2}=95.8 \%\right.$ p $<0.001)$. The prevalence of MetS was $37.0 \%$ among adult Palestinians population ranging from 17 to 59.5\%. Subgroup analysis did not show source of heterogeneity based on subject's health status and MetS criteria.

CONCLUSION: Our meta-analysis clearly demonstrates that MetS is highly prevalent (37.0\%) among Palestinian adults. The high prevalence of MetS in Palestine should be seriously considered and planners should take steps to reduce it.

KEYWORDS: Prevalence, Metabolic syndrome, Meta-analysis, Palestine 


\section{INTRODUCTION}

It is observable that cardiovascular disease (CVD) and associated premature mortality have become a major concern in adult Palestinian population. In addition, people with MetS carry a much higher risk of CVD. MetS is a cluster of the most dangerous heart attack risk factors: diabetes, raised fasting plasma glucose, abdominal obesity, high cholesterol and high blood pressure (1-3). Based on reports, around 20-25 percent of the world's adult population have the MetS, and mortality rate among these people is twice as likely from heart attack, and three times as likely from stroke compared with people without MetS (3). In addition, the risk of developing type 2 diabetes among people with MetS is a fivefold (4). The clustering of CVD risk factors that typifies MetS is now considered to be the driving force for a new CVD epidemic (5). A number of expert groups have developed clinical criteria for the MetS. The most widely accepted of these were produced by the World Health Organization (WHO), the European Group for the Study of Insulin Resistance, the National Cholesterol Education Program-Third Adult Treatment Panel (NCEP/ATP III) and the International Diabetes Federation definition (IDF) (4-7).

The underlying cause of the MetS continues to challenge the experts but both insulin resistance and central obesity are considered the main causes (8). Genetic and environmental factors such as sedentary lifestyle, unhealthy dietary habits and high rates of cigarette smoking contribute to MetS development (9). In the general population, genetic and geographical environment differences might partially be responsible for the prevalence rates of MetS alter in different countries (9-12). Despite the importance of MetS in the context of metabolic and CVD in Palestine, few studies have described the prevalence of MetS and its related factors, hence restricting the quality of information available on the magnitude of this problem in the country. Gathering reliable information about the prevalence of MetS and its related factors in various populations can be very effective in the planning and use of preventive strategies for such diseases. Moreover, the current burden of MetS in Palestine is unknown.
Therefore, to help provide a clearer picture of the current situation in Palestine, we conducted a meta-analysis with an objective to clarify the prevalence rate of MetS and its related factors among the adult Palestinian population. The findings of this study will give baseline information about the prevalence of MetS and its related factors among the adult Palestinian population.

\section{METHODS}

Literature searches of PubMed, Scopus and Google scholar for publications in English were conducted in December 2014 up to February 2015 for all published data related to MetS in Palestine. Unpublished studies were not retrieved. To maximize the possibility of including all relevant studies, the following search strategy was used: (("Metabolic syndrome" OR "Syndrome of Affluence" OR "Plurimetabolic syndrome" OR "Syndrome X" OR "Metabolic syndrome X" OR "Reaven syndrome" OR "Insulin resistance syndrome" OR "Insulin resistance/hyperinsulinemia syndrome" OR "Atherothrombogenic syndrome" OR "Metabolic cardiovascular syndrome" OR "Syndrome X plus" "Deadly quartet" OR "Cardiovascular and metabolic syndrome" OR "Dysmetabolic syndrome X" OR "MetSyn" OR "Wohlstands syndrome" OR "Android obesity syndrome" OR "Dysmetabolic syndrome" OR "Hypertriglyceridemic syndrome" OR "Obesity syndrome" OR "Obesity dyslipidemia syndrome" OR "Hypertriglyceridemic waist") AND (Palestine OR West Bank OR Jenin OR Tubas OR Tukarml OR Nablus OR Qalqilya OR Salfit OR Ramallah OR Jericho OR Jerusalem OR Bethlehem OR Hebron OR Gaza Strip OR North Gaza OR Gaza Governorate OR Deir Al Balah OR Khan Yunis OR Rafah)). Thirteen, thirty-three and six articles were found in the databases PubMed, Google scholar and Scopus, respectively. To satisfy the analysis requirements and reduce selection deviation, the selected studies were required to meet the following criteria: 1) a population-based study conducted in Palestine; 2) studies with random sampling and sufficient information of sample size, 3) crude prevalence of MetS, 4)

DOI: http://dx.doi.org/10.4314/ejhs.v27i1.10 
participants aged of 15 years or above and 5) use of MetS diagnostic criteria. The total number of articles found was 49. According to the PRISMA flow chart, ten of the articles after duplicates were removed, twenty-one of articles were excluded because their title and abstract were not related to prevalence of MetS and not compatible with the study objective while eighteen of full text articles were assessed for eligibility. Only eight papers were included in the final analysis. After determining the qualified papers, data were extracted according to a standard protocol. To improve accuracy and critical appraisal, data extraction was conducted by two independent researchers, and disputes between researchers were resolved through consensus. Generic, methodological and statistical information was extracted from the eligible studies which reported MetS prevalence including age, sex, geographical location, year of publication, sample size and prevalence of MetS. A random effect metaanalysis was conducted on crude MetS prevalence rates, and heterogeneity was assessed by Cochran's Q and $I^{2}$ tests $(13,14)$. The presence of heterogeneity was determined by the chi ${ }^{2}$ test with a significance level of $<0.1$ combined with an $I^{2}$ statistic for estimates of inconsistency within the meta-analyses. The $I^{2}$ statistics estimates the percent of observed between-study variability due to heterogeneity rather than chance; ranges from 0 to 100 percent. For this review, we determined that $I^{2}$ values above $75 \%$ were indicative of significant heterogeneity warranting analysis with a random effect model as opposed to the fixed effect model to adjust for the observed variability between studies. Subgroup analyses were also performed according to the predefined criteria including health status, age and criteria used for MetS. Egger test was conducted to examine potential publication bias.

\section{RESULTS}

Flow chart of the study is shown in Figure 1. A total of 49 articles were found in the initial search and after removing duplicates and screening, eight articles were included in the study. Included studies were from 2001 to 2013 in West Bank, Jerusalem and Gaza Strip. The total sample size of the eight included studies was 2937 subjects (ranging 163-992). The age range of the participants was 16 to 65 , and the criteria used to assess MetS in these studies were NCEP/ATP III, WHO and IDF criteria; NCEP/ATP III was the most often used. Characteristics and data of the articles are presented in Table 1. The prevalence of MetS by random effect was $37.0 \%$ (955 $\mathrm{CI}=0.25 \%-0.45 \%$ ) (Figure 2). The heterogeneity was $I^{2}=95.8 \%, \mathrm{p}=0.000$ ). The subgroup analysis by subject health status and MetS criteria (IDF vs. NCEP/ATP III) did not remove heterogeneity among studies. There was no evidence of publication bias (Egger's test $\beta 0$ : 11.8; $\mathrm{p}=0.07$ ). With respect to factors associated with MetS, our results showed that the prevalence of MetS varied depending on the definition used for diagnosing MetS. IDF's definition provided significantly higher prevalence $($ mean $=43.7 \%)$ of MetS in Palestinian adults compared to NCEP/ATP III's definition (mean $=37.27 \%)$ and WHO's definition (mean $=17 \%$ ). In addition, the MetS is more prevalent in women $($ mean $=42.55 \%)$ than men (mean $=35.41 \%)$. Also, the prevalence of overall obesity was $51.95 \%$ and $37.8 \%$ in women and men respectively. Furthermore, in our metaanalysis, the studies which used IDF criteria for MetS showed that the prevalence of MetS increased by age. Moreover, our results showed that the prevalence of MetS appeared to be high among unhealthy participants (studies were done on patients) $($ mean $=48.67 \%)$ compared to healthy participants (mean $=25.62 \%$ ) in all included studies. Finally, our results showed that the prevalence of MetS in Palestinian's adults residing in northern Palestine (West Bank governorates $($ mean $=38.05 \%)$ ) was higher than those residing in southern Palestine (Gaza Strip governorates $($ mean $=36.25 \%)$ ).

DOI: http://dx.doi.org/10.4314/ejhs.v27i1.10 


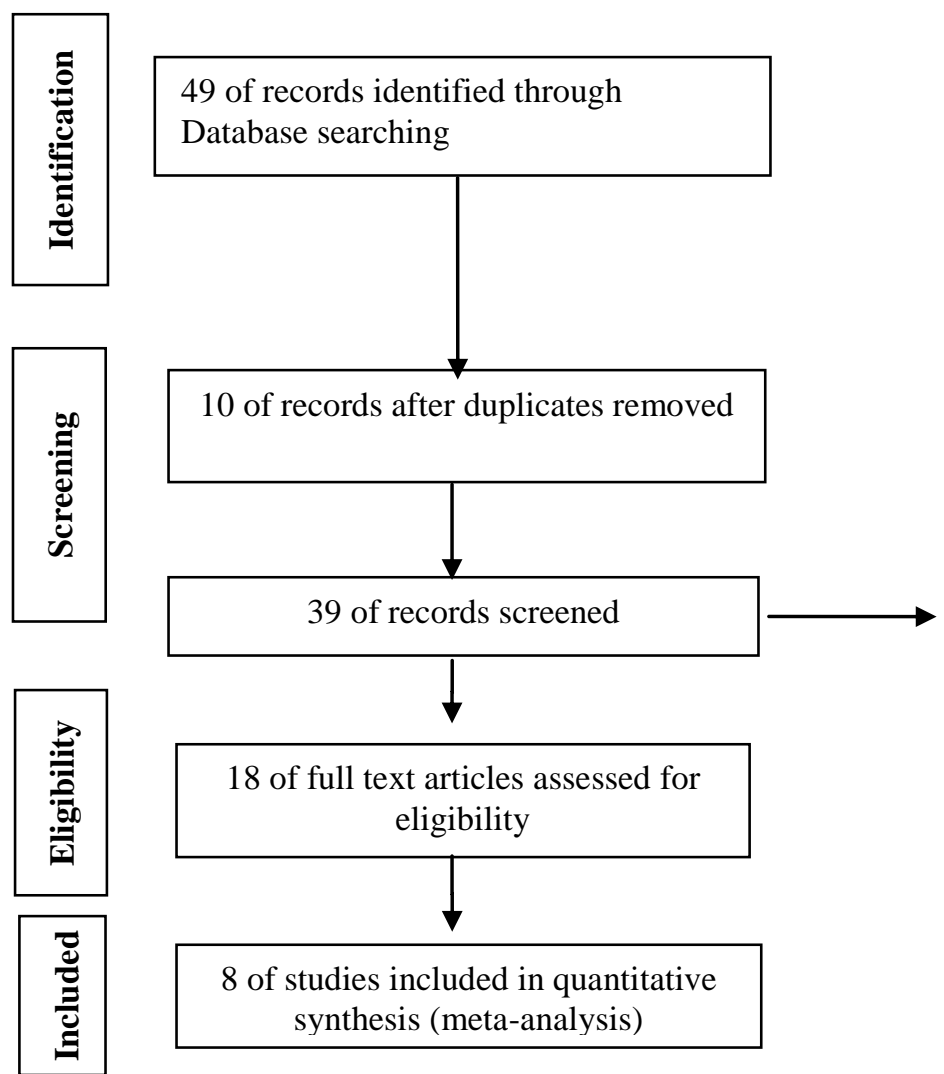

21 of records were excluded; reasons: Title and abstract were not related to prevalence of metabolic syndrome. Not compatible with study objective. Data not in usable format.

Figure 1: Results of the systematic literature search

Najwa R, et al
Abu Sham'a, et al
Amal Jamee, et al
Hanan F, et al
Mahmoud M, et al
Mahmoud S, et al
Mahmoud S, et al
Sweileh, et al
Overall (I-squared = $99.5 \%, \mathrm{p}=0.000)$
NOTE: Weights are from random effects analysis

Figure 2: The prevalence of MetS.

DOI: http://dx.doi.org/10.4314/ejhs.v27i1.10 
The Prevalence of Metabolic Syndrome...

Abdel H.. et al

Table 1: Characteristics of MetS included studies in meta-analysis

\begin{tabular}{|c|c|c|c|c|c|c|c|c|c|c|c|c|c|}
\hline 目 & 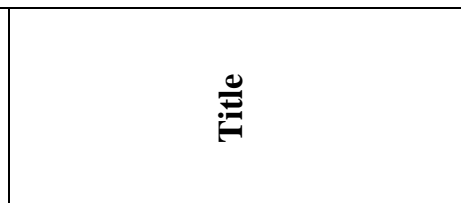 & $\frac{n}{E}$ & Eั & $\ddot{z}$ & 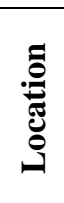 & 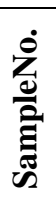 & $\stackrel{0}{\stackrel{0}{e}}$ & 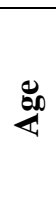 & $\sum_{i=1}^{\infty}$ & $\sum_{i=1}^{\infty}$ & 空 & : & 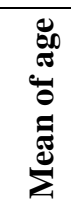 \\
\hline$\stackrel{\overbrace{}}{=}$ & 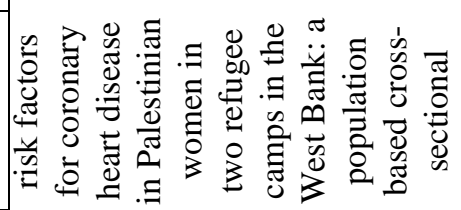 & 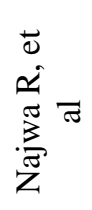 & 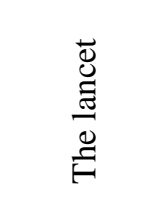 & $\stackrel{\circ}{\stackrel{0}{\circ}}$ & 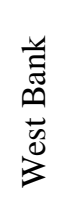 & $\stackrel{8}{8}$ & 萱 & $\begin{array}{l}n \\
\dot{1} \\
\dot{q} \\
\dot{q}\end{array}$ & $\begin{array}{l}80 \\
8 \\
\infty \\
\infty\end{array}$ & $\begin{array}{l}8 \\
\infty \\
n\end{array}$ & 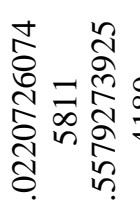 & 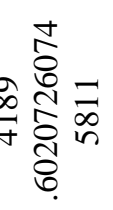 & 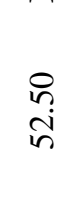 \\
\hline$\underset{\sim}{\stackrel{Ð}{\rightleftarrows}}$ & 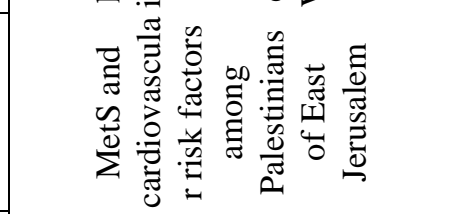 & 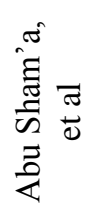 & 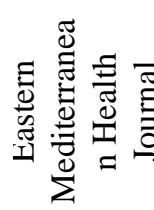 & ஓे & 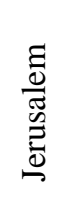 & $\stackrel{\text { Iे }}{\text { m }}$ & 狊 & $\underset{\wedge}{\stackrel{N}{\Lambda}}$ & $\begin{array}{l}\dot{b} \\
\dot{m} \\
m\end{array}$ & $\underset{m}{\stackrel{D}{n}}$ & 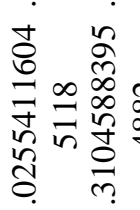 & 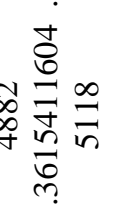 & $\underset{\substack{8 \\
\infty \\
\infty \\
\infty}}{ }$ \\
\hline 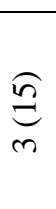 & 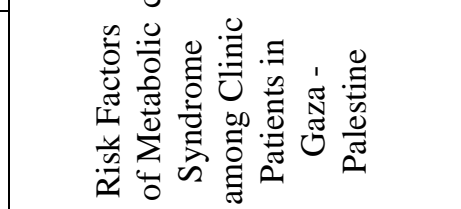 & 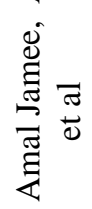 & 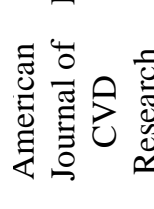 & $\frac{m}{\stackrel{n}{~}}$ & 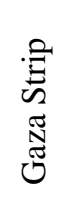 & $\tilde{6}$ & 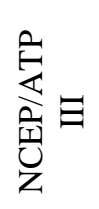 & $\begin{array}{l}\infty \\
0 \\
\grave{d}\end{array}$ & $\begin{array}{l}80 \\
8 \\
\frac{0}{2} \\
\text { in }\end{array}$ & 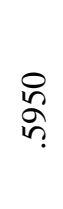 & 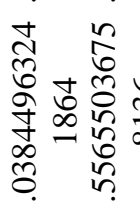 & 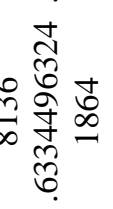 & $\frac{\stackrel{n}{n}}{n}$ \\
\hline$\underset{\forall}{\stackrel{6}{\sigma}}$ & 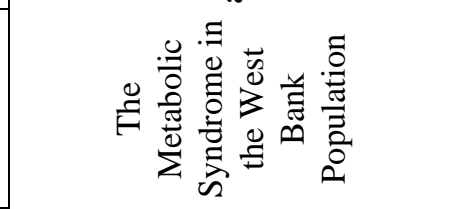 & 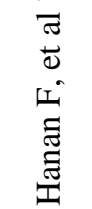 & 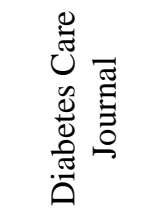 & 홍 & 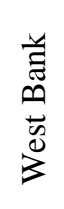 & ส้ & $\stackrel{0}{\frac{0}{1}}$ & $\begin{array}{l}n \\
0 \\
1 \\
0\end{array}$ & $\frac{8}{8}$ & § & 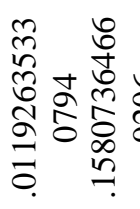 & 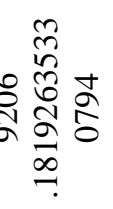 & 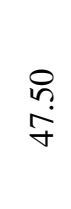 \\
\hline$\underset{n}{E}$ & 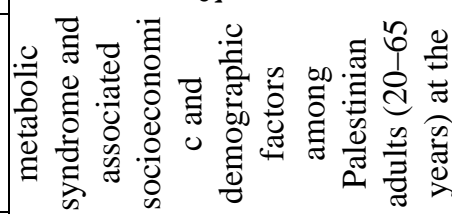 & 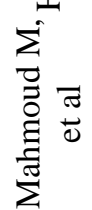 & 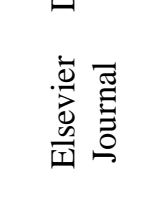 & $\overrightarrow{\bar{D}}$ & 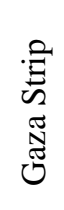 & 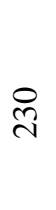 & 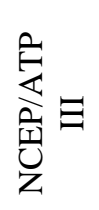 & 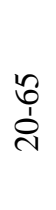 & 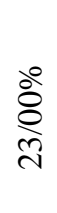 & $\begin{array}{l}8 \\
\text { } \\
\text { ก̣ }\end{array}$ & 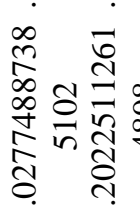 & 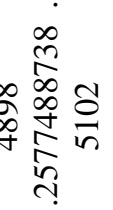 & $\begin{array}{l}\underset{+}{+} \\
\underset{f}{ }\end{array}$ \\
\hline$\underset{\sigma}{\stackrel{\infty}{=}}$ & 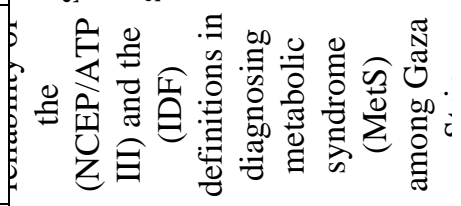 & 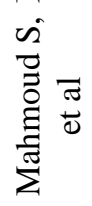 & 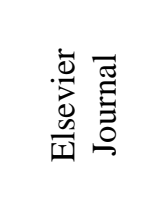 & $\stackrel{\sim}{\stackrel{\sim}{*}}$ & $\begin{array}{l}\text { : } \\
\text { W } \\
\widetilde{\tilde{N}} \\
\tilde{N}\end{array}$ & $\underset{\sim}{\stackrel{N}{ }}$ & 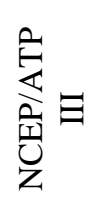 & $\begin{array}{l}n \\
0 \\
0 \\
d\end{array}$ & $\frac{\stackrel{8}{8}}{\stackrel{\text { }}{2}}$ & $\begin{array}{l}\stackrel{0}{0} \\
\text { }\end{array}$ & 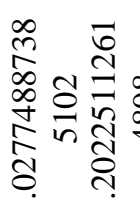 & 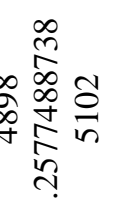 & 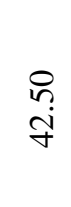 \\
\hline$\underset{\sim}{\stackrel{\infty}{\infty}}$ & 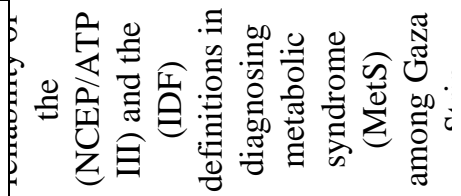 & 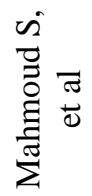 & 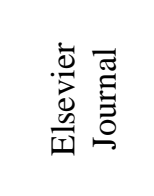 & ¿্ণ & 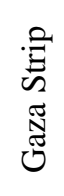 & $\stackrel{\overbrace{}}{\sim}$ & $\stackrel{5}{\mathrm{G}}$ & 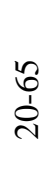 & $\begin{array}{l}\stackrel{0}{8} \\
\stackrel{0}{n} \\
\text { n }\end{array}$ & $\begin{array}{l}\stackrel{n}{n} \\
\text { ñ }\end{array}$ & 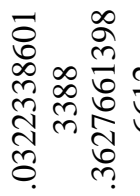 & 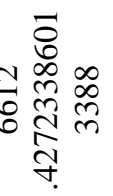 & 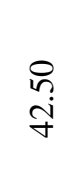 \\
\hline$\underset{\infty}{\stackrel{\overbrace{}}{\rightleftharpoons}}$ & 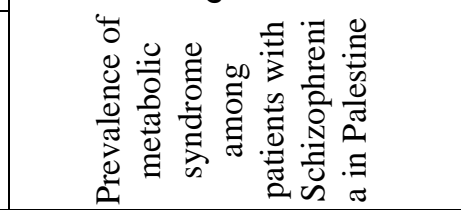 & 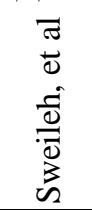 & 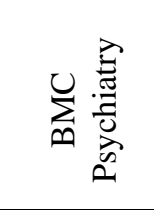 & $\overline{\mathrm{N}}$ & 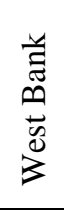 & $\stackrel{\gtrless}{\sim}$ & 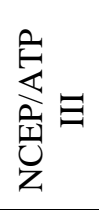 & $\stackrel{\vec{\wedge}}{\stackrel{0}{1}}$ & $\frac{8}{8}$ & 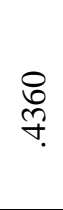 & 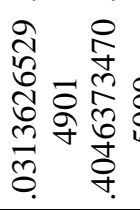 & 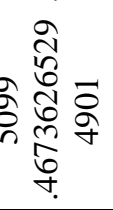 & לִ \\
\hline
\end{tabular}

\section{DISCUSSION}

To the author's knowledge, the present meta-analysis is the first to demonstrate the prevalence of MetS in Palestinian's adults. In this meta-analysis, after random effect model meta-analysis, results showed that the prevalence of MetS in Palestinian adults is about $37.0 \%$. There was a considerable heterogeneity among the included studies. In order to reduce the heterogeneity, we divided the studies into

DOI: http://dx.doi.org/10.4314/ejhs.v27i1.10 
subgroups by subject's health status and MetS criteria to achieve homogeneity. Nonetheless, homogeneity was not achieved. MetS is a global problem, approximately around a quarter of the world's adult population has MetS (15), and one fourth of the European adult population was estimated to have MetS (15). In the Middle East, the MetS affects about one in four people and its prevalence increases with age (16). In our metaanalysis, the prevalence of MetS was relatively high compared to US (17), Europe (18), China (19) and Iran (20) and varied depending on the definition used for diagnosing MetS. IDF's definition provided significantly higher prevalence (mean $=43.7 \%$ ) of MetS in Palestinian adults compared to NCEP/ATP III's definition (mean $=37.27 \%$ ) and WHO's definition $($ mean $=17 \%)(10-12,21-24)$. The high prevalence of MetS may be related in part to differences in the definitions used and the populations studied. Therefore, the use of a single criterion would identify the prevalence of MetS with greater sensitivity. Other factors that could explain the difference include different lifestyles and different socioeconomic status. According to previous studies in Jordan (25), Turkey (26), Tunisia (27), Saudi (28), and Iran (20), the prevalences of MetS were $36.3 \%, 33.9 \%, 24.3 \%, 21 \%$, and $34.7 \%$ respectively. The prevalence of MetS in those studies is approximately the same as what was found in this review. Furthermore, the prevalence of MetS was higher among females in these countries $(20,25$ 28). Our results showed that the MetS is more prevalent among women (mean $=42.55 \%$ ) than among men $($ mean $=35.41 \%$ ) which is a common finding in previous studies (29-32). In Arab countries, women had a higher prevalence of MetS compared to men (33-35). This also fits with the Palestinians and is related to the higher incidence of obesity among women (36-38).

In our meta-analysis, the prevalence of overall obesity was $51.95 \%$ and $37.8 \%$ in women and men respectively. Multiple pregnancies, high unemployment, over-eating, little physical activity and a loss of interest in body shape after marriage and childbirth (which is related to cultural and social restrictions) are associated with increased prevalence of obesity in women (36). Age is another important and strongly associated risk factor for MetS (39). In our meta-analysis, the studies which used IDF's criteria for MetS showed that the prevalence of MetS increased by age $(11,12,23)$. The positive associations of aging with hypertension, diabetes and obesity were illustrated among Palestinian adult population (21). Moreover, continuously increasing weight in women with age could in part be an effect of premenopausal and menopausal disturbances which was found to be associated with visceral fat accumulation and acute increase of insulin resistance (40). In addition, our results showed that the prevalence of MetS appeared to be high among unhealthy participants (studies were done on patients) (mean $=48.67 \%$ ) compared to healthy participants $($ mean $=25.62 \%)$ in all included studies. Furthermore, our results showed that the prevalence of MetS in Palestinian adults residing in northern Palestine (West Bank governorates (mean = $38.05 \%)$ ) was higher than those residing in southern Palestine (Gaza Strip governorates (mean = $36.25 \%)$ ) indicated that the prevalence of MetS may be affected by different geographical area.

One limitation of this meta-analysis was the heterogeneity in the criteria used to define MetS among studies. The strength of this study is that it is the first study which shows the prevalence of MetS in Palestinian adults. The present meta-analysis study may provide a baseline data on the prevalence of MetS in Palestinian's adults and can guide other researchers to design new studies.

In conclusion, our meta-analysis clearly shows that MetS is highly prevalent (37.0\%) among Palestinian adults. The high prevalence of MetS in Palestine should be seriously considered by stakeholders to reduce it. Future prospective studies investigating the prevalence of MetS and its components among Palestinian population would benefit from using a single, universally accepted diagnostic tool for MetS. This would enable prevalence estimates to be compared and monitored.

\section{REFERENCES}

1. Alberti K, Zimmet P, Shaw J. Metabolic syndrome - a new world-wide definition. A consensus statement from the international diabetes federation. Diabetic medicine. 2006;23(5):469-80.

2. Alberti KGM, Zimmet P, Shaw J, Group IETFC. The metabolic syndrome - a new worldwide definition. The Lancet. 2005;366(9491):105962.

3. Mohan V, Deepa M. The metabolic syndrome in developing countries. Diabetes Voice. 2006;51(Special Issue). 
4. Stern MP, Williams K, González-Villalpando C, Hunt KJ, Haffner SM. Does the metabolic syndrome improve identification of individuals at risk of type 2 diabetes and/or cardiovascular disease? Diabetes care. 2004;27(11):2676-81.

5. Whiting DR, Guariguata L, Weil C, Shaw J. IDF diabetes atlas: global estimates of the prevalence of diabetes for 2011 and 2030. Diabetes research and clinical practice. 2011;94(3):31121.

6. Ceriello A, Colagiuri S. International Diabetes Federation guideline for management of postmeal glucose: a review of recommendations. Diabetic Medicine. 2008;25(10):1151-6.

7. Expert Panel on Detection E. Executive summary of the third report of the National Cholesterol Education Program (NCEP) expert panel on Detection, Evaluation, and Treatment of high blood cholesterol in adults (Adult Treatment Panel III). Jama. 2001;285(19):2486.

8. Definition W. diagnosis and classification of diabetes mellitus and its complications: report of a WHO consultation. Geneva: World Health Organization. 1999.

9. Balkau B, Charles M-A. Comment on the provisional report from the WHO consultation. Diabetic medicine. 1999;16(5):442-3.

10. Carr DB, Utzschneider KM, Hull RL, Kodama $\mathrm{K}$, Retzlaff $\mathrm{BM}$, Brunzell JD, et al. Intraabdominal fat is a major determinant of the National Cholesterol Education Program Adult Treatment Panel III criteria for the metabolic syndrome. Diabetes. 2004;53(8):2087-94.

11. Weiss R, Bremer AA, Lustig RH. What is metabolic syndrome, and why are children getting it? Annals of the New York Academy of Sciences. 2013;1281(1):123-40.

12. Jamee A, Abed Y, Abutawila H. Risk Factors of Metabolic Syndrome among Clinic Patients in Gaza-Palestine. American Journal of Cardiovascular Disease Research. 2013;1(1):20-4.

13. Rizkallah-Khader N. Parity and coronary heart disease risk factors among Palestinian women in two refugee camps on the West Bank: London School of Hygiene \& Tropical Medicine; 2009.

14. Abu Sham'a R, Darwazah A, Kufri F, Yassin I, Torok N. MetS and cardiovascular risk factors among Palestinians of East Jerusalem. EMHJ Eastern Mediterranean Health Journal, 15 (6), 1464-1473, 2009.
15. Higgins JP, Thompson SG, Deeks JJ, Altman DG. Measuring inconsistency in meta-analyses. BMJ. 2003 Sep 6;327(7414):557-60. PubMed PMID: 12958120. Pubmed Central PMCID: 192859. Epub 2003/09/06. eng.

16. Peters JL, Sutton AJ, Jones DR, Abrams KR, Rushton L. Contour-enhanced meta-analysis funnel plots help distinguish publication bias from other causes of asymmetry. Journal of clinical epidemiology. 2008;61(10):991-6.

17. Dunstan DW, Zimmet PZ, Welborn TA, De Courten MP, Cameron AJ, Sicree RA, et al. The Rising Prevalence of Diabetes and Impaired Glucose Tolerance The Australian Diabetes, Obesity and Lifestyle Study. Diabetes care. 2002;25(5):829-34.

18. Sliem HA, Ahmed S, Nemr N, El-Sherif I. Metabolic syndrome in the Middle East. Indian journal of endocrinology and metabolism. 2012;16(1):67.

19. Park Y-W, Zhu S, Palaniappan L, Heshka S, Carnethon MR, Heymsfield SB. The metabolic syndrome: prevalence and associated risk factor findings in the US population from the Third National Health and Nutrition Examination Survey, 1988-1994. Archives of internal medicine. 2003;163(4):427-36.

20. Hu G, Qiao Q, Tuomilehto J, Balkau B, BorchJohnsen K, Pyorala K. Prevalence of the metabolic syndrome and its relation to all-cause and cardiovascular mortality in nondiabetic European men and women. Archives of internal medicine. 2004;164(10):1066-76.

21. Gu D, Reynolds K, Wu X, Chen J, Duan X, Reynolds RF, et al. Prevalence of the metabolic syndrome and overweight among adults in China. The Lancet. 2005;365(9468):1398-405.

22. Azizi F, Salehi P, Etemadi A, Zahedi-Asl S. Prevalence of metabolic syndrome in an urban population: Tehran Lipid and Glucose Study. Diabetes research and clinical practice. 2003;61(1):29-37.

23. Abdul-Rahim HF, Husseini A, Bjertness E, Giacaman R, Gordon NH, Jervell J. The metabolic syndrome in the West Bank population an urban-rural comparison. Diabetes care. 2001;24(2):275-9.

24. Sirdah MM, Al Laham NA, Ghali ASA. Prevalence of metabolic syndrome and associated socioeconomic and demographic factors among palestinian adults (20-65 years) at

DOI: http://dx.doi.org/10.4314/ejhs.v27i1.10 
the Gaza Strip. Diabetes \& Metabolic Syndrome: Clinical Research \& Reviews. 2011;5(2):93-7.

25. Sirdah MM, Ghali ASA, Al Laham NA. The reliability of the National Cholesterol Education Program's Adult Treatment Panel III (NCEP/ATP III) and the International Diabetes Federation (IDF) definitions in diagnosing metabolic syndrome (MetS) among Gaza Strip Palestinians. Diabetes \& Metabolic Syndrome: Clinical Research \& Reviews. 2012;6(1):4-8.

26. Sweileh WM, Sa'ed HZ, Dalal SA, Ibwini S, Sawalha AF, Ali I. Prevalence of metabolic syndrome among patients with schizophrenia in Palestine. BMC psychiatry. 2012;12(1):235.

27. Khader Y, Bateiha A, El-Khateeb M, Al-Shaikh A, Ajlouni K. High prevalence of the metabolic syndrome among Northern Jordanians. Journal of Diabetes and its Complications. 2007;21(4):214-9.

28. Kozan O, Oguz A, Abaci A, Erol C, Ongen Z, Temizhan A, et al. Prevalence of the metabolic syndrome among Turkish adults. European journal of clinical nutrition. 2007;61(4):548-53.

29. Bouguerra R, Alberti H, Smida H, Salem L, Rayana C, El Atti J, et al. Waist circumference cut-off points for identification of abdominal obesity among the tunisian adult population. Diabetes, Obesity and Metabolism. 2007;9(6):859-68.

30. Bahijri SM, Al Raddadi RM. The importance of local criteria in the diagnosis of metabolic syndrome in Saudi Arabia. Therapeutic advances in endocrinology and metabolism. 2013;4(2):51-9.

31. Cohn T, Prud'homme D, Streiner D, Kameh H, Remington G. Characterizing coronary heart disease risk in chronic schizophrenia: high prevalence of the metabolic syndrome. Can $J$ Psychiatry. 2004;49(11):753-60.

32. De Hert MA, van Winkel R, Van Eyck D, Hanssens L, Wampers M, Scheen A, et al. Prevalence of the metabolic syndrome in patients with schizophrenia treated with antipsychotic medication. Schizophrenia research. 2006;83(1):87-93.

33. Hägg S, Lindblom Y, Mjörndal T, Adolfsson R. High prevalence of the metabolic syndrome among a Swedish cohort of patients with schizophrenia. International clinical psychopharmacology. 2006;21(2):93-8.

34. McEvoy JP, Meyer JM, Goff DC, Nasrallah HA, Davis SM, Sullivan L, et al. Prevalence of the metabolic syndrome in patients with schizophrenia: baseline results from the Clinical Antipsychotic Trials of Intervention Effectiveness (CATIE) schizophrenia trial and comparison with national estimates from NHANES III. Schizophrenia research. 2005;80(1):19-32.

35. Al-Lawati JA, Mohammed AJ, Al-Hinai HQ, Jousilahti P. Prevalence of the metabolic syndrome among Omani adults. Diabetes care. 2003;26(6):1781-5.

36. Harzallah F, Alberti H, Ben Khalifa F. The metabolic syndrome in an Arab population: a first look at the new International Diabetes Federation criteria. Diabetic medicine. 2006;23(4):441-4.

37. Jaber LA, Brown MB, Hammad A, Zhu Q, Herman WH. The prevalence of the metabolic syndrome among Arab Americans. Diabetes care. 2004;27(1):234-8.

38. Abdul-Rahim H, Holmboe-Ottesen G, Stene L, Husseini A, Giacaman R, Jervell J, et al. Obesity in a rural and an urban Palestinian West Bank population. International Journal of Obesity. 2003;27(1):140-6.

39. Rahim A, Abu-Rmeileh N, Husseini A, Ottensen G, Jervell J, Bjertness E. Obesity and selected co-morbidities in an urban Palestine population. Int J Obs Rel Met Dis. 2001;25:1736-40.

40. Kaluski DN, Berry E. Prevalence of obesity in Israel. Obesity reviews. 2005;6(2):115-6.

41. Dokras A, Bochner M, Hollinrake E, Markham S, VanVoorhis B, Jagasia DH. Screening women with polycystic ovary syndrome for metabolic syndrome. Obstetrics \& Gynecology. 2005;106(1):131-7.

42. Fujimoto WY, Bergstrom RW, Boyko EJ, Chen K-W, Kahn SE, Leonetti DL, et al. Type 2 diabetes and the metabolic syndrome in Japanese Americans. Diabetes research and clinical practice. 2000;50:S73-S6. 